\title{
Transforming Workplace Learning: A Qualitative Inquiry into Adopting Massive Open Online Courses into Corporate Learning and Development
}

\author{
Agnieszka Żur ${ }^{1, *}\left(\mathbb{D}\right.$ and Christian Friedl ${ }^{2}$ \\ 1 Departmnet of Entrepreneurship and Innovation, Cracow University of Economics, Rakowicka 27, \\ 31-510 Cracow, Poland \\ 2 Institute of International Management, FH Joanneum University of Applied Sciences, Alte Poststrasse 149, \\ 8020 Graz, Austria; Christian.Friedl@fh-joanneum.at \\ * Correspondence: zura@uek.krakow.pl
}

Citation: Żur, A.; Friedl, C.

Transforming Workplace Learning: A

Qualitative Inquiry into Adopting

Massive Open Online Courses into

Corporate Learning and

Development. Educ. Sci. 2021, 11, 295.

https://doi.org/10.3390/

educsci11060295

Academic Editor: Randall S. Davies

Received: 23 April 2021

Accepted: 8 June 2021

Published: 15 June 2021

Publisher's Note: MDPI stays neutral with regard to jurisdictional claims in published maps and institutional affiliations.

Copyright: (c) 2021 by the authors. Licensee MDPI, Basel, Switzerland. This article is an open access article distributed under the terms and conditions of the Creative Commons Attribution (CC BY) license (https:/ / creativecommons.org/licenses/by/ $4.0 /)$.

\begin{abstract}
Despite the wide acknowledgement of the knowledge-based economy, the need for lifelong learning and quickly growing open online resources, Massive Open Online Courses (MOOCs) are not common means of corporate learning and development programs. The aim of this study is to identify key factors determining the adoption of MOOCs in corporate workplace learning programs. In this exploratory research, the authors employ empirical data from 36 in-depth interviews with corporate managers directly responsible for learning and development practices. Findings provide potential explanations for the mismatch between a generally positive attitude towards MOOCs and their still low adoption rate by identifying expectations towards MOOCs, as well as major reservations. We find that while corporations recognize the opportunities MOOCs can introduce into workplace learning, elevated expectations, negative first-time experiences and objective barriers inhibit MOOC adoption in corporate learning and development programs. It is among the first to expose the perspective of organizations at an early stage of adopting MOOCs. The findings provide a novel contribution to both workplace learning scholarship as well as practical recommendations which can inform HR managers' decisions in regard to adopting digital means in workplace learning.
\end{abstract}

Keywords: workplace learning; massive open online course; eLearning; technology adoption; digital learning

\section{Introduction}

Online learning has become widely regarded as a valuable option in a variety of contexts, including the corporate context. As recently evidenced during the COVID-19 pandemic, today's quickly expanding digital technologies provide tools and functionalities that enable organizations to deliver traditional learning and development programs online. Digital means provide new opportunities in the form of open-source content, online consulting and support centers or open-source e-learning courses and training programs [1,2]. They play an increasingly important role in the development of corporate employees [3-5]. This trend has amplified during the COVID-19 pandemic, which has brought about a general rise in the use of online learning platforms [5]

While research has addressed the adoption of digital platform-based training and education among individuals, the corporate level factors of adoption of these means remain largely unknown. Some have signaled that the digital technology perspective of corporate learning is under-researched and that there is a wide gap in our understanding of corporate learning in the digital age [6,7]. Given the fast evolution of digital technologies, dynamic changes in business arenas and an unprecedented influx of innovation, it seems critical for corporations to take advantage of the variety of digital learning formats to capture up-to-date knowledge for their employees in feasible and cost-effective ways. 
This study explores the factors influencing the adoption of Massive Open Online Courses (MOOCs) by corporations. Over the last decade, within the corporate context, MOOCs have been used for education and training purposes, as well as recruiting, marketing, and brand awareness [8-11]. MOOCs can enhance the cost-effectiveness of learning and development in organizations and digital learning analytics enable the measurement of learning effectiveness [12-14] and thus the effective management of talent development [15]. Despite their potential benefits, MOOCs remain largely underexploited by the corporate world $[7,16]$. Hence the driving research question for this study is: what factors determine the use of MOOCs in corporate learning and development programs? This exploratory study seeks to identify the expectations, reservations and reported benefits of MOOC adoption and to capture the often sensitive contextual insights from the corporate world. As MOOC potential benefits are experienced primarily in large organizations, where scalability is an important issue, large corporations present a logical setting for this study.

The intended contribution is to deliver an organizational perspective on MOOC adoption rather than an individual one. The study is based on data gathered from 36 managers directly responsible for the learning and development practices of their respective companies and who therefore represent their organization's outlook toward MOOCs.

The paper begins by introducing the key concepts with a theoretical background. It then describes the research strategy and methodology used in the research. Next, it presents the findings, followed by the theoretical contribution and practical implications. The paper concludes with final inferences and suggestions for future research.

\section{Theoretical Background}

\subsection{Corporate Learning and Development in the Digital Age}

Digital technologies have radically reshaped and oftentimes disrupted the learning and development ecosystems in the business world, although with notable differences across populations $[17,18]$. Online learning, or eLearning, combines technology with learning, delivered using telecommunication and information technologies, and supporting learning and organizational goals [19]. Low costs, convenience, standardized delivery, self-paced learning, and a variety of available content make online learning a high priority for many corporations [16], a trend surely intensified during the COVID-19 pandemic. Autio et al. [20] have outlined three important benefits of digital learning formats. First, digitalization reduces the need for assets and physical infrastructure and thus also the cost of communication. Second, it promotes disintermediation, enabling direct connections between various actors without any intermediary Third, it drives generativity, which enables dispersed, often very distant and/or different audiences to create and take advantage of digital platforms. These three factors radically broaden the access to learning resources and break down the limitations of traditional learning formats. The exploitation of these properties results in creating new network learning paradigms with roots in social constructivism, based on equality, networking, and seamless connections with digital communities at its core $[21,22]$. Online learning communities often become the means of informal learning practices for individual employees, or the "new coffee rooms" [23]. Providing employees with multiple and diverse opportunities for informal learning seems important taken that formal corporate education programs are often generically structured and difficult to adapt to particular individual needs [24]. Online formats, on the other hand, present considerable possibilities of tailoring content to individual employee needs.

Digital learning formats present certain advantages over traditional ones and help to explain the rise of corporate online learning as a promising avenue for both research and practice. Hence, demand for online learning and development formats is rising exponentially.

\subsection{Massive Open Online Courses and their Adoption by the Corporate World}

The two last decades have brought a rapid rise of various online learning formats, one of them being Massive Open Online Courses (MOOCs), designed for a massive number of participants, open to anyone without entry qualifications, and offered for free [25]. 
Large MOOC platforms such as EdX, Coursera and Udacity are the main global providers. Numerous smaller platforms exist in parallel. In 2019, more than 900 universities offered 13,500 courses to 110 million learners [26]. Recently we observe a target shift from the traditional university to business learners as the increase of MOOC uptake by corporations over the last years has been amplified during the COVID-19 crisis in 2020 [5,27].

There are reasons to believe that MOOCs could help corporations adapt their training programs to a rapidly changing workforce [28]. MOOCs are open, online, on-demand, mobile, self-paced, social and offer flexible delivery, making them a suitable tool for training in flexible work arrangements, including remote work [29,30]. The wide selection of available MOOCs creates an opportunity for designing personalized talent development plans and with the right guidance can foster self-directed learning, which as recent research indicates can in turn positively impact job performance [31]. Compared to other e-learning formats, the novelty and value-addition of MOOCs lie in massive participation, inducing social learning and interaction with distant and dispersed learners, and access to completely new knowledge pools. They enable just-in-time employee learning by connecting geographically and institutionally distant actors in real-time [32].

While existing studies explain the core success factors of MOOCs, as well as their various formats, expansion strategies and knowledge facilitation [33-36], significantly less attention has been devoted and less empirical evidence produced on corporate adoption of MOOCs. This is surprising, given how employees continue to be besieged by a variety of information technologies and tools, and even more so during the COVID-19 pandemic, regardless of whether the organization or the individual is ready for this shift.

Jeyaraj and Sabherwal [37] have proposed four stages of information technology adoption: (i) non-adoption (no use of available technologies, due to lack of awareness or due to rejection); (ii) experimentation (testing new technologies to understand their features and assess their usefulness); (iii) partial adoption (using only a subset of features of the available technology); (iv) full adoption (exploiting the full potential of a given technology). Examples of these four stages can be observed among firms adopting MOOCs for corporate learning and development. For example, SAP developed its own corporate MOOC platform which gathers more than 700,000 learners in more than 280 courses on both company-specific and general topics [38]. It clearly falls under the category "full adoption", as do Adidas, McAfee, Deutsche Telekom, Google and L'Oréal [29,39].

However, most corporations fall into the "experimenting" and "partial adoption" categories. Even though employees increasingly are involved in MOOCs, only 5\% of MOOC employee-learners take courses with the official support of their companies [40]. Despite numerous examples of experimentation, authors agree that on the whole large corporations still fail to exploit the opportunities that MOOCs offer, including cost-effectiveness and scalability $[40,41]$. Empirical evidence on this inconsistency is scarce. eLearning scholarship has studied general organizational barriers, including up-front investments, technology issues, inappropriate content and cultural acceptance [4]. As those works refer to eLearning in general, not its particular formats, they fail to capture recent developments. Hence, evidence is missing whether those barriers continue to be valid for MOOC provision today. Work remains to be done on why corporations do not exploit the potential of MOOCs.

\section{Materials and Methods}

Through gaining insight into the expectations, reservations and reported benefits of MOOCs, this study seeks to understand the factors behind MOOC adoption in corporate learning and development programs. As these issues remain neglected, this study presents perhaps the first scholarly attempt to explore why and how MOOCs are adopted by corporations in the early phases of adoption. The object of this study is fairly unexplored and involves complex, multidimensional organizational level factors, which need to be explored incrementally [42], hence this study is based on a qualitative interpretative research strategy. 


\subsection{Purposive Sampling}

The study is based on a purposive sampling selection, where "sampling proceeds according to the relevance of the case instead of the representativeness" [43], p.121. As the goal of the study was to gain insights into the drivers and hindering factors of the adoption process, we sought to connect with business organizations still at an early stage of adopting MOOCs into their learning and development programs. For the purpose of case selection, we adapted Jeyaraj and Sabherwal's [37] criteria for four stages of adopting information technology. Full adopters are defined as corporations formally exploiting the full potential of MOOCs by using and promoting the use of MOOCs among their employees by providing them with a repository of recommended MOOCs. Non-adopters are defined as those firms which do not use MOOCs in any way, due to lack of awareness or rejection of a given technology. All firms which do not fall into these two categories were classified as partial adopters-that is, those who experiment or use MOOCs to a limited extent and are therefore of interest for the purpose of this study.

As ours is an exploratory study, a diverse range of settings was selected to ensure diverse manifestations of the studied phenomena [44]. The initial list of potential respondents was created by analyzing data available in international corporate enterprise directories as well as by directly accessing individuals through private and professional networks. As a part of the purposive sampling done, snowball sampling was also used to increase variation in the data. The authors were able to achieve variance in industry profiles to provide a cross-sectoral and interdisciplinary study lens. The companies included in the study represented the following sectors: automotive, oil and gas, energy, banking, business services, chemical, construction, electronics, finance, telecom and hospitality.

The initial contact was made by email and served to determine whether the organization is a non-adopter, partial adopter or full adopter of MOOCs. Our respondents were senior managers, responsible for training, learning and/or talent development and were able to describe the perceptions and practices related to MOOC adoption across the entire company. Results presented below are an outcome of 36 interviews with those partial adopters who agreed to share their corporate experience with MOOCs. The size of the sample fits the established criteria for a typical interpretative exploratory study and ensured an acceptable level of data saturation [42].

\subsection{Data Collection}

The study is based on data collected via semi-structured interviews and the examination of secondary materials. Secondary data consisted of external data sources relevant to the case obtained from publicly available media (company websites, newspaper articles, earlier interviews with company representatives) and provided helpful background information for the collection of primary data and was employed in later data analysis and triangulation.

Primary data were collected through semi-structured interviews with corporate managers conducted online between May and November 2020. The interviews addressed the following broad thematic areas: (1) familiarity with MOOCs, (2) perception of MOOCs, (3) expectations of MOOCs, (4) adoption of MOOCs (challenges, benefits). The themes covered respectively: reservations towards MOOCs, factors influencing the adoption of MOOCs and the benefits experienced. The interview started with a broad question, for example, "What is the perception of MOOCs within your organization?". Depending on the details of the answers, follow-up in-depth questions were prepared, for example: "How are MOOCs perceived by those employees who used them?", "How are they perceived by your department?", "Why do you think that is?", "What shapes that perception in your opinion?". Each interview lasted between 60 and $180 \mathrm{~min}$ and was recorded for content analysis purposes. The interviews were carried out in English and all respondents were assured of their anonymity. 


\subsection{Triangulation}

Triangulation refers to the means of incorporating different perspectives on an issue under study, producing different levels of knowledge that can promote the quality of the study. Denzin and Lincoln [42] distinguish four types of triangulation: theory triangulation, data triangulation, investigator triangulation and methodological triangulation. In this study, triangulation was applied to both research design and analysis. Investigator triangulation was applied by following a routine of systematic comparison of different researcher's influences on the analyzed themes and minimize bias resulting from prior research experience. This process proved to be very valuable at the data analysis stage; coding demands researchers to challenge each other and understand different perspectives.

We used triangulation as part of our sampling strategy. We followed the principle of data triangulation which refers to the differentiation of various data sources differentiated by time, place and person [42]. Purposive sampling and gradual selection of respondents ensure the integration of various perspectives and experiences of different temporal and local setting [43] to advance our understanding of the studied phenomenon. We sought to include different industry representatives in our sample as well as to differentiate the manifestations of partial adoption of MOOCs.

Finally, we applied triangulation to data analysis to raise the validity of our research [43]. We did not rely only on the data collected through interviews, but used secondary data sources to back up the evidence provided by the respondents or to gain a better understanding of the company's profile. Using data located at "different levels" contributes to the reliability of the data and validity of the study.

\subsection{Data Analysis}

The first step was, based on respondents' testimonies, to evaluate the level of familiarity with MOOCs and the adoption of MOOCs by the firm. This immersion in each transcript at a time was a process of sense-making and textual analysis [42]. The particular corporate experiences, perceptions, potential reservations and adaptation benefits were mapped out. During this phase, respondents were sometimes re-contacted to clarify or elaborate on certain facts or themes and to eliminate interpretation bias. Semi-open coding was carried out with the use of content analysis software [45].

Next, a meta-level analysis was conducted by comparing similarities and differences across cases for each research theme, looking for shared aspects of experiences, common clusters of meaning and aggregating themes across accounts (first-order categories). In this phase, we sought to identify, among the aggregated categories, potential manifestations of the Unified Theory of Acceptance and Use of Technology (UTAUT model) dimensions [46], a framework based on four core constructs: Performance Expectancy, Effort Expectancy, Social Influence and Facilitating Conditions as predictors of user behaviors in adopting information technology. These manifestations are marked in the figures presenting the data organization. The final stage of data analysis involved developing meta clusters of meanings related to the adoption of MOOCs by corporations (second-order aggregated categories).

\section{Results}

Our final results are structured around three broad categories: (1) perception and expectations of MOOCs, (2) reservations towards the adoption of MOOCs, and (3) the benefits of adopting MOOCs. The dimensions of the UTAUT model identified along with the data analysis are marked in each of the results figures.

\subsection{Perception and Expectations towards MOOCs}

Respondents expressed their corporation's expectations of MOOCs and online training in general (see Figure 1). Most of these expectations reflect "performance expectancy" factors in the UTAUT model and refer to the practicality of the content, high-quality course 
materials, personalization (content tailored to the level, needs and wishes of the learner), as well as alignment with company culture, policy and practice.

\section{Examples of respondents' testimonies}

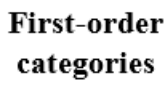

\section{Second-order cumulative categories}

"Any knowledge assimilated during a course, (traditional or not) must be applicable and relevant for day-to-day business activities"

"If I am to recommend or introduce MOOCs at work, it must be worth the effort for employees and the organization"

"Dedicated corporate MOOCs can help with onboarding new employees"

"If MOOCs are to be of use, they must refer to our own corporate reality, our procedures and our culture"

"The best MOOCs would be those made specifically for our company and our employees"

"It seems like a great way to train people on specific niche topics that only a few people in our company might need"

"If a MOOC can provide training on highly specialized issues, then we should consider it"

"People expect to receive precisely what they are looking for, what they need here and now"

"With hundreds of thousands of MOOCs out there, anyone can find something of interest"

"MOOCs seem like a great way to develop your particular professional interest on your own, if you want to know more after corporate regular training"

"MOOCs can serve as a means of acquainting people with online learning, digital environments, communities and raise employees' digital literacy"

"MOOCs should be available anytime anywhere, accessible 24/7 and be easy to handle, user friendly"
Practical applicability of new knowledge and skills in the workplace

(performance expectancy)

Servicing standard, repetitive corporate training

(performance expectancy)

Servicing rare small-scale needs

(performance expectancy)

Personalised content; tailored to the level, needs and wishes of the learner

(effort expectancy)

Development of themes and topics introduced via regular corporate training (performance expectancy)

Digital upskilling (performance expectancy)

\section{Convenience}

(facilitating conditions)
Organizational learning:

MOOCs can become costeffective means of training to various groups of corporate audiences, replacing faceto-face training in several areas.
Individual learning:

MOOCs can provide support for personal education and multiple training needs of company employees

Figure 1. Corporate perceptions and expectations of MOOCs. 
Most respondents believe that online training and MOOCs should be complementary to traditional face-to-face training/education. Whilst interviewees perceived the development of skills to be the main objective, they also highlight the possibility of increasing digital literacy via online education and training.

The organizations interviewed observed as well that MOOCs can enhance lifelong learning while integrating professional development in feasible ways; the learner should be able to access resources outside of their work context and on multiple devices (such as a mobile device), enabling learning to occur at a time convenient to the learner.

Overall, the findings suggest that corporations display similar expectations to all learning and development modes, regardless of their format. Two sets of expectations in regard to MOOCs refer to:

- the value-addition they bring to the company as a whole (cost savings, effectiveness)

- the enhanced learning opportunities and learning experience they present to employees (a convenient, personalized learning journey for each individual employee).

\subsection{Factors Hindering the Adoption of MOOCs in Corporate Learning and Development}

Respondents highlighted a number of issues that represent the companies' reservations towards adopting MOOCs for their learning and development programs (see Figure 2). Many indicated that selecting the most appropriate MOOC from the very wide range of existing courses can be challenging. In addition to doubts about reliability, respondents admitted that courses offered were often not aligned with their company's culture, practice and current challenges or that they remain too general for specific corporate needs and core business competencies.

Legal limitations and corporate affairs were often signaled as major barriers to MOOCs' massive adoption. Confidentiality and personal data protection issues were considered a particularly critical barrier; as MOOCs remain on the provider's platform and hence employee and/or company data are collected and stored by a third party outside the company.

Thanks to their flexibility and time-saving potential, MOOCs were considered by interviewees to facilitate easier access to learning materials (Figure 3). Respondents noted that MOOCs boost learner confidence, as learners can quickly fill in any knowledge gaps they might have or develop general transferable skills. Respondents agree that MOOCs are potentially a cost-effective way to ensure that employees keep their skills and professional knowledge up to date. They identified the potential to increase their employees' network and access to completely new pools of knowledge, not accessible via internal company training. They also appreciate the opportunity employees have to engage with specialists and use up-to-date material as highly valuable aspects of MOOCs.

Since most MOOCs are massive in terms of participants, and addressed to anyone around the world, several respondents identify their natural potential in promoting and gaining intercultural competencies. This was a highly valued side effect recognized by corporations using MOOCs. 
"I once tried to get an idea which MOOCs could work for all of our organization, but after one hour I gave up, there are just too many"

"We would need to rely on a provider that would do the preselection for us" We provide our employees with a directory of recommended courses, our talent development department takes care of that"

"In self-paced MOOCs you receive programmed messages and feedback. That can be very annoying"

"Only moderated MOOCs make sense, otherwise you are working with a machine"

"MOOCs require experience of e-learning, not everybody has the experience" "Not everybody is digitally savvy enough"

"Most MOOCs are too general for our corporate needs"

"If we adopt MOOCs within our company on a massive scale, they need to be fully aligned with our driving values, our culture, our mission"

"MOOCs are made for everyone, so maybe sometimes risk being for no one" "Corporations need very specific areas of knowledge, specific to our industry, our markets etc"

"Our legal department discouraged my team from using MOOCs"

"Our internal firewalls do not allow employees to access some content - they need to use personal computers"

"MOOCs often require learners to share their experience. This creates a risk of corporate data or confidential information to leak out"

"The problem is that the MOOC provider stores user data on their server" "We can only use online courses run and stored on our server. It is company policy"

"We are very careful when it comes to employee learning online, like MOOCs" "We had very bad experience in the past"

"Online learning cannot be fully trusted - only face-to-face trainers can be held

"The information must be 100\% accurate, otherwise people lose trust"

"How can I know if I can fully rely on what my people learn in MOOCs?"

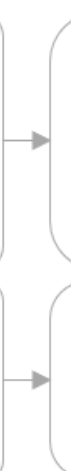

Too many MOOCs, people can get lost (anxiety)

Directories needed

(facilitating conditions)

Require digital literacy (anxiety)

Impersonal (general attitude)

MOOCs not aligned with corporate culture (performance expectancy)

Topics too general (performance expectancy)

Internal corporate regulations

(facilitating conditions)

Confidentiality (facilitating conditions)

Employee data safety (facilitating conditions)

Prior negative experiences (general attitude)

Reliability (performance expectancy)
Digital anxiety

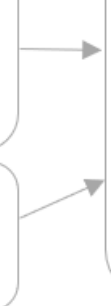

Mismatch between content and corporate needs

Corporate data safety and security

Validity issues

Figure 2. Corporate reservations about adopting MOOCs. 


\section{Examples of respondents' testimonies}

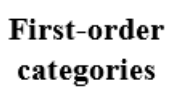

Second-order

cumulative

categories

"Our employees are self-driven in choosing what knowledge they need to update or fill in"

"It's a great way to access university resources if you need to be up-to-date"

"There are many MOOCs dedicated to growing general transferable skills - we encourage employees to take advantage of those"

"We provide employees with a MOOC directory to grow their interpersonal skills"

"MOOCs are available to anyone who needs them, at any time"

"If some employees need to learn new things they are encouraged to search for the right courses online themselves, and this way they can learn quickly, much quicker than if we were to organize company training"

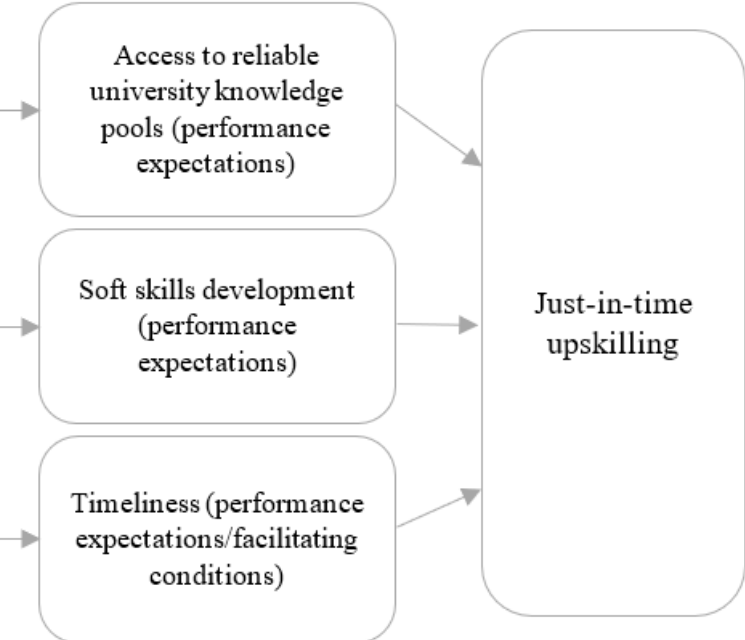

"With MOOCs our employees can learn with people from all around the world, from many different industries"

"Taking a course with people from different countries and companies inspires new ideas, which the company can benefit from"

"MOOCs connect our employees with experts and professionals from our field" "Employees are very satisfied to grow their personal and professional networks through learning online"
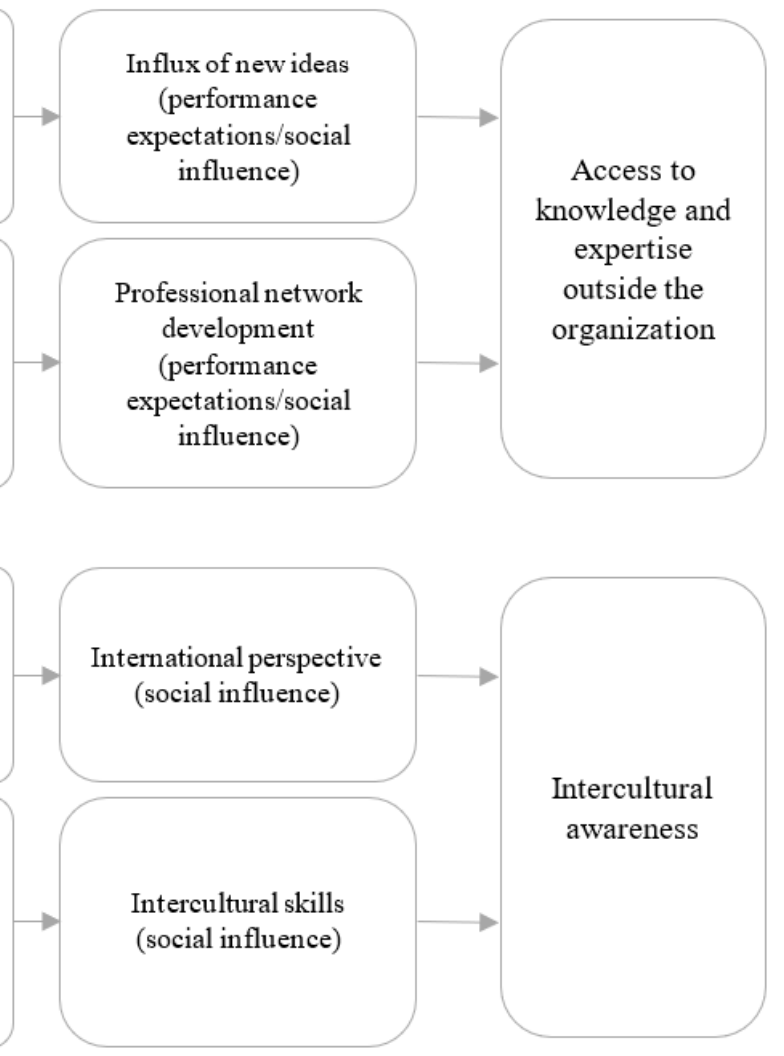

"Exposure to knowledge and expertise around the world is a huge benefit" "Our employees enjoy learning in these intercultural teams and gaining access to examples from all around the world"

"Learning through MOOCs has increased intercultural competence within the company"

"Online learning develops their intercultural skills - it makes our job easier"

Figure 3. Benefits of MOOCs for corporate learning and development.

\section{Discussion and Implications}

This study offers important cognitive and theoretical contributions to workplace learning scholarship. The first contribution is a potential explanation for why, given the rather high awareness and positive attitude, MOOC adoption level remains low. Analysis of the findings reveals a combination of factors. 
The recorded expectations towards MOOCs in our study are rather high, maybe too high. On top of expectations relevant for any type of corporate learning and development, such as thematic relevance, practicality or cost-effectiveness, several refer to MOOCs specifically, such as convenience or digital upskilling. Our findings confirm prior studies which hypothesize that the user expectations towards MOOCs are often too high or even unrealistic [29]. For example, the expectation that a MOOC offering full alignment with the company's values, culture and mission appears to be attributable to non-realistic expectations. Any external online training designed for a massive audience might well fail to reach that bar. Second, with the massive number of MOOCs available to corporations, and the noted difficulties with finding an appropriate course, companies easily become discouraged and do not adopt MOOCs into their corporate ecosystem. These effects have been observed in European corporations (e.g., Erste Bank; see [47]).

Our results show that corporate uptake of MOOCs is further limited by objective factors, particularly risking the outflow of employee data and company-sensitive information. Companies are not willing to take the risk of confidential information leaks and they are unable to weaken their digital firewalls to enable MOOC content access from company computers. These formal barriers, high expectations coupled with initial negative experiences explain the low MOOC adoption rate despite their generally being well-received.

The second contribution this research makes concerns the benefits. The identification of perceived and experienced benefits of MOOC adoption is a valuable input into the literature on the digital transformation of corporate learning and development programs. Work done to this point has generally not examined MOOC adoption outcomes but has been limited to theorizing conceptual and discussion papers. This study suggests that corporations that adopt MOOCs into their learning and development programs experience significant benefits. The leading benefits identified by our study are: just-in-time individualized upskilling, access to external knowledge pools and intercultural exchange. Gaining a broader international perspective through MOOCs, interacting with learners from all around the world and developing intercultural competence in the context of exploratory learning and inter-organizational learning is a value-addition that managers should bear in mind. MOOCs can also introduce and/or strengthen the social learning aspect, network effects and inter-organizational learning-factors identified in prior studies as critical for contemporary workplace learning [48,49]. The MOOC adopters in our sample acknowledge and appreciate the potential to establish informal learning networks. Our study suggests that MOOCs can serve as a viable introduction to new knowledge pools in various digital learning ecosystems. This is an important finding, that information sharing, access to new ideas, alternative viewpoints and perspectives mediates employee innovative behaviors [50]. Particularly in the distance economy of the COVID-19 pandemic, learning with and from various distant networks has become increasingly relevant.

Results do not show cost savings to be a key benefit of MOOCs, even if potential cost-savings are enabled thanks to their scalability. However, reports from corporations experimenting with MOOC development themselves do not confirm a cost-saving benefit, at least not at an early stage of adoption [51]. MOOCs lower costs when implemented on an institutional level with multiple iterations and a broader course portfolio [52], thus creating synergies, but not as a one-time endeavour. Given that corporations expect online learning to bring direct cost efficiencies [53], a lack of immediate savings might further explain the low uptake of MOOCs.

Our study offers useful methodological implications for future studies concentrating on technology adoption in workplace learning. Prior studies revealed that UTAUT was a useful framework with which to analyze MOOC adoption and has been used thus far to examine MOOC adoption among individuals, particularly students' learning behaviors e.g., $[54,55]$. To the best of our knowledge, no research has tested the usefulness of the UTAUT model to study the adoption of information technology by organizations. Hence, this study provides insights into whether the model captures all dimensions relevant to corporate MOOC adoption. Our study has recorded the manifestation of all dimen- 
sions of the UTAUT model within our respondent group. Expectations towards MOOCs were expressed predominantly by testimonies falling into the category of "performance expectancy", while reservations mostly were categorized as "anxiety" and "facilitating conditions". This is consistent with other studies on individual ICT adoption [54]. Finally, the identified benefits fall within the categories of performance expectations, facilitating conditions and social influence. Despite the identification of particular UTAUT dimensions, we argue that in its current form, the UTAUT model cannot serve to predict or explain MOOC adoption levels in organizations. It fails to capture the factors that play a critical role in the organizational level perspective-corporate data safety and security. Our study shows that corporate uptake of MOOCs is strongly limited by employee data security and the outflow of company-sensitive information. Our research results suggest that alignment with corporate policy can be a decisive factor; even if all others are met, this factor can effectively block MOOC adoption. We therefore recommend the UTAUT model be refined by adding a new dimension-"alignment with company policy," with sub-measures established to capture its particular areas.

On top of theoretical and methodological contribution, our study also offers important practical implications for corporate managers and MOOC developers. As the aim of this study was to identify key factors determining the adoption of MOOCs in corporate workplace learning programs, our findings suggest that four factors are critical in this regard: (i) proficiency of HR managers in planning the MOOC experience for employees, (ii) clearly defined goals and expectations of adopting MOOCs, (iii) preselection of platform provider to secure company and employee data, and (iv) preselection of MOOCs that fit employees' learning needs and company values.

Our findings highlight the need for educating HR managers about available MOOC offers, as well as about quality control options MOOCs enable. MOOCs are open, traceable, trackable, accessible and evaluated by a massive number of users [56] and as such are more closely monitored than individual training done behind closed doors. In addition, automated quality assurance with learning analytics is making progress [57]. MOOCs not only make learning analytics accessible, but also offer proof of what employees learn and with what results. Finally, Bogdan et al. [58] call for additional skills for HR managers and trainers themselves to curate and assess MOOCs and make use of learning analytics. Credit Suisse [59] and Erste Bank [47] have taken such steps.

Our study suggests that corporations need to be clear about why MOOCs are being implemented and what they are expected to achieve. Unfortunately, these are all too often reduced to a discussion of offline vs. online, as several statements in our sample signal. However, exploiting both formats as complementary offers [58]-less competing, more completing-promises great benefits.

Our research results signal that there is an urgent need for intermediary services to help corporate managers identify the right platforms and the right courses for their employees-done either by internal MOOC-experienced employees or an external consultancy. Numerous existing studies indicate that MOOCs are first embraced by employees, then by their organizations [60-62]. We suggest that this presents an opportunity-proactive employees might support their HR managers in collecting MOOC experiences and co-creating suggested MOOC repositories.

The identified factors of MOOC adoption by corporations can bring us a step closer to closing the gap between MOOC design/content and corporate needs/requirement. They can also be used to inform future decisions of both corporate managers and MOOC developers, who can use them to successfully transform and optimize offline with online modes in workplace learning.

\section{Conclusions}

This study extends our understanding of the factors driving and hindering the digital transformation of corporate learning and development programs, particularly in the area of MOOC adoption.(Appendix A) It is among the first to expose the perspective of 
organizations at an early stage of adopting MOOCs. We identify factors responsible for a low adoption rate, specifically false presumptions, elevated expectations and objective barriers, such as company internal data safety and security. The findings of our study have relevance and utility for informing HRD policy decisions in regard to adopting digital means in workplace learning programs.

The study has several limitations. First, as this is an explorative qualitative study, generality is strongly limited. Moreover, there is only a single point of reference and data collected through single-respondent interviews risk being biased by the personal opinion of the responded and not fully aligned with the company's overall stance. This limitation was partly mitigated by the analysis of secondary data. Additionally, this potential bias was somewhat mitigated by the fact that the individuals interviewed were senior managers responsible for learning and development and talent development programs at their organizations. This research can serve as a starting point for further studies, particularly to examine and test the factors that transform partial adopters into full adopters. Taken the dynamics of the COVID-19 pandemic, future research should evaluate MOOC adoption by the corporate world post-COVID-19 pandemic.

Author Contributions: Conceptualization, A.Ż. and C.F.; Funding acquisition, A.Ż.; Methodology, A.Ż.; Software, A.Ż.; Validation, A.Ż. and C.F.; Investigation, A.Ż. and C.F.; Data curation, A.Ż. and C.F.; Writing—original draft preparation, A.Ż. and C.F.; Writing—review and editing, A.Ż. and C.F.; Supervision, A.Ż. All authors have read and agreed to the published version of the manuscript.

Funding: This project has been financed by the Minister of Education and Science within the "Regional Initiative of Excellence" Programme for 2019-2022. Project no.: 021/RID/2018/19. Total financing: 11897 131,40 PLN.

Data Availability Statement: The data presented in this study are available on request from the corresponding author. Full data not publicly available to secure respondent anonymity.

Conflicts of Interest: The authors declare no conflict of interest.

Appendix A

\begin{tabular}{ccccc}
\hline Position & $\begin{array}{c}\text { Size of Firm } \\
\text { (Employment } \\
\text { Worldwide) }\end{array}$ & Industry & MOOC Adoption \\
\hline R1 & General HR executive & Above 20,000 & energy & 2 \\
R2 & Talent development & Above 150,000 & automotive & 1,4 \\
R3 & General HR executive & Above 50,000 & banking & 2 \\
R4 & Talent development & Above 3000 & business services & 1 \\
R5 & Employee training & Above 20,000 & oil and gas & 2,3 \\
R6 & Employee training & Above 5000 & business services & 1,3 \\
R7 & General HR executive & Above 3000 & finance & 1,3 \\
R8 & Talent development & Above 100,000 & telecom & 3 \\
R9 & Talent development & Above 4000 & business services & 2,4 \\
R10 & Employee training & Above 200,000 & automotive & 1 \\
R11 & General HR executive & Above 70,000 & hospitality & 1 \\
R12 & General HR executive & Above 4000 & finance & 1,3 \\
R13 & Employee training & Above 200,000 & telecom & $1,2,3,4$ \\
R14 & Employee training & Above 6000 & hospitality & 3,4 \\
R15 & Employee training & Above 100,000 & automotive & 2 \\
R16 & General HR executive & Above 10,000 & business services & 2 \\
R17 & Talent development & Above 30,000 & banking & 3 \\
R18 & Employee training & Above 5000 & finance & $1,3,4$ \\
R19 & Talent development & Above 20,000 & banking & 2,3 \\
R20 & Employee training & Above 3000 & business services & 1 \\
R21 & Employee training & Above 5000 & business services & 3 \\
R22 & Talent development & Above 50,000 & oil and gas & 3 \\
\hline
\end{tabular}




\begin{tabular}{lcccc}
\hline Position & $\begin{array}{c}\text { Size of Firm } \\
\text { (Employment } \\
\text { Worldwide) }\end{array}$ & Industry & MOOC Adoption \\
\hline R23 & Talent development & Above 7000 & chemical & $1,2,3$ \\
R24 & Employee training & Above 15,000 & hospitality & 2 \\
R25 & General HR executive & Above 5000 & hospitality & 1 \\
R26 & Employee training & Above 20,000 & chemical & 3,4 \\
R27 & Employee training & Above 150,000 & telecom & $1,2,3,4$ \\
R28 & Talent development & Above 120,000 & telecom & 2,3 \\
R29 & Employee training & Above 3000 & construction & 1 \\
R30 & General HR executive & Above 2000 & construction & 1 \\
R31 & General HR executive & Above 40,000 & banking & 1,4 \\
R32 & Employee training & Above 15,000 & chemical & 1 \\
R33 & Talent development & Above 120,000 & electronics & $1,2,3,4$ \\
R34 & Employee training & Above 10,000 & business services & 2,3 \\
R35 & Talent development & Above 10,000 & electronics & 1,3 \\
R36 & General HR executive & Above 7000 & construction & 1 \\
\hline
\end{tabular}

1-Used once or twice in blended training formats; 3-Use occasionally in blended training formats; 3-Promoting employee uptake; 4-Past experience of co-creating MOOCs.

\section{References}

1. Morcillo, P.; Rodriguez-Anton, J.M.; Rubio, L. Corporate culture and innovation: In search of the perfect relationship. Int. J. Innov. Learn. 2007, 4, 547-570. [CrossRef]

2. Pisoni, G. Strategies for pan-european implementation of blended learning for innovation and entrepreneurship (i\&e) education. Educ. Sci. 2019, 9, 124.

3. Ellis, P.F.; Kuznia, K.D. Corporate eLearning impact on employees. Glob. J. Bus. Res. 2014, 8, 1.

4. Kumar, P. Corporate e-Learning: Possibilities, Promises, and Realities. DESIDOC. J. Libr. Inf. Technol. $2011,31$.

5. Rindlisbacher, C. Surging Interest in Online Education. In Class Central MOOC Report. 2020. Available online: https://www. classcentral.com/report/surging-interest-in-online-education/ (accessed on 3 August 2020).

6. Dodson, M.N.; Kitburi, K.; Berge, Z.L. Possibilities for MOOCs in corporate training and development. Perform. Improv. 2015, 54, 14-21. [CrossRef]

7. Kimiloglu, H.; Ozturan, M.; Kutlu, B. Perceptions about and attitude toward the usage of e-learning in corporate training. Comput. Hum. Behav. 2017, 72, 339-349. [CrossRef]

8. Egloffstein, M.; Ifenthaler, D. Employee perspectives on MOOCs for workplace learning. TechTrends 2017, 61, 65-70. [CrossRef]

9. Grossman, R. Are Massive Online Courses in Your Future? In Organizational and Employee Development Special Report; SHRM: Alexandria, VA, USA, 2013.

10. Radford, A.W.; Coningham, B.; Horn, L. MOOCs: Not just for college students-How organizations can use MOOCs for Professional Development. Employ. Relat. Today 2015, 41, 1-15. [CrossRef]

11. Sreeleakha, P.; Manikandan, N. The Way Forward with MOOCs-Professional Development Perspectives. Am. Int. J. Res. Humanit. Arts Soc. Sci. 2015, 15, 29-32.

12. Khalil, M.; Ebner, M. Learning analytics: Principles and constraints. In Proceedings of the EdMedia \& Innovate Learning 2015, Kona, HI, USA, 22 June 2015; Carliner, S., Fulford, C., Ostashewski, N., Eds.; Association for the Advancement of Computing in Education (AACE): Waynesville, NC, USA, 2015; pp. 1789-1799.

13. Tseng, S.F.; Tsao, Y.W.; Yu, L.C.; Chan, C.L.; Lai, R.K. Who will pass? Analyzing learner behaviors in MOOCs. Res. Pract. Technol. Enhanc. Learn. 2016, 11, 8. [CrossRef]

14. Klemke, R.; Eradze, M.; Antonaci, A. The flipped MOOC: Using gamification and learning analytics in MOOC design-A conceptual approach. Educ. Sci. 2018, 8, 25. [CrossRef]

15. Sousa, M.J.; Rocha, Á. Corporate Digital Learning-Proposal of Learning Analytics Model. In World Conference on Information Systems and Technologies; Springer: Cham, Switzerland, 2018; pp. 1016-1025.

16. Beinicke, A.; Kyndt, E. Evidence-based actions for maximising training effectiveness in corporate E-learning and classroom training. Stud. Contin. Educ. 2020, 42, 256-276. [CrossRef]

17. Harwood, S.A. The domestication of online technologies by smaller businesses and the 'busy day'. Inf. Organ. 2011, 21, 84-106. [CrossRef]

18. Passey, D. Technology-enhanced learning: Rethinking the term, the concept and its theoretical background. Br. J. Educ. Technol. 2019, 50, 972-986. [CrossRef]

19. Chen, E.T. Successful E-Learning in corporations. Commun. IIMA 2008, 8, 5.

20. Autio, E.; Nambisan, S.; Thomas, L.D.; Wright, M. Digital affordances, spatial affordances, and the genesis of entrepreneurial ecosystems. Strateg. Entrep. J. 2018, 12, 72-95. [CrossRef] 
21. Albors, J.; Ramos, J.C.; Hervas, J.L. New learning network paradigms: Communities of objectives, crowdsourcing, wikis and open source. Int. J. Inf. Manag. 2008, 28, 194-202. [CrossRef]

22. Ke, F.; Hoadley, C. Evaluating online learning communities. Educ. Technol. Res. Dev. 2009, 57, 487. [CrossRef]

23. García-Peñalvo, F.J.; Colomo-Palacios, R.; Lytras, M.D. Informal learning in work environments: Training with the Social Web in the workplace. Behav. Inf. Technol. 2012, 31, 753-755. [CrossRef]

24. Decius, J.; Schaper, N.; Seifert, A. Informal workplace learning: Development and validation of a measure. Hum. Resour. Dev. Q. 2019, 30, 495-535. [CrossRef]

25. Kaplan, A.M.; Haenlein, M. Higher education and the digital revolution: About MOOCs, SPOCs, social media, and the cookie monster. Business Horizons 2016, 59, 441-450. [CrossRef]

26. Shah, D. By The Numbers: MOOCs in, Class Central. 2019. Available online: https://www.classcentral.com/report/mooc-stats2019/ (accessed on 2 August 2020).

27. Shah, D. MOOCWatch 23: Pandemic Brings MOOCs Back in the Spotlight. In Class Central. Available online: https://www. classcentral.com/report/moocwatch-23-moocs-back-in-the-spotlight/ (accessed on 2 August 2020).

28. Ladge, J.; Kossek, E.; Little, L.; Montanye, M.; Perrigino, M.; Wanberg, C.; Bodner, T.; Csillag, B.; Duffy, M.; Gettings, P.; et al. Changing Organizations for a Changing Workforce: Improving Work-Life Implementation and Adaptation. Acad. Manag. Proc. 2019, 2019, 17281.

29. Friedl, C.; Staubitz, T. Corporate MOOC trends. In The 2018 OpenupEd Trend Report on MOOCs; Jansen, D., Konings, L., Eds.; EADTU: Maastricht, The Netherlands, 2018; pp. 35-38.

30. Santandreu, D.C.; Shah, M.A.; Riggs, K.; Connor, M. MOOCs and upskilling in Australia: A qualitative literature study. Cogent Educ. 2019, 6, 1687392. [CrossRef]

31. Lejeune, C.; Beausaert, S.; Raemdonck, I. The impact on employees' job performance of exercising self-directed learning within personal development plan practice. Int. J. Hum. Resour. Manag. 2021, 32, 1086-1112. [CrossRef]

32. Gori, S.; Robes, J. Social Learning: Vernetztes Lernen im Unternehmen. In Personalentwicklung. Themen, Trends, Best Practices 2016; Schwuchow, K., Gutmann, J., Eds.; Haufe-Lexware: Freiburg, Germany; München, Germany, 2016.

33. Conole, G.G. MOOCs as disruptive technologies: Strategies for enhancing the learner experience and quality of MOOCs. Rev. Educ. Distancia 2013, 39, 1-17. [CrossRef]

34. Kizilcec, R.F.; Saltarelli, A.J.; Reich, J.; Cohen, G.L. Closing global achievement gaps in MOOCs. Science 2017, 355, 251-252. [CrossRef] [PubMed]

35. Zawacki-Richter, O.; Bozkurt, A.; Alturki, U.; Aldraiweesh, A. What research says about MOOCs-An explorative content analysis. Int. Rev. Res. Open Distrib. Learn. 2018, 19. [CrossRef]

36. Żur, A. Two Heads Are Better Than One-Entrepreneurial Continuous Learning through Massive Open Online Courses. Educ. Sci. 2020, 10, 62. [CrossRef]

37. Jeyaraj, A.; Sabherwal, R. Adoption of information systems innovations by individuals: A study of processes involving contextual, adopter, and influencer actions. Inf. Organ. 2008, 18, 205-234. [CrossRef]

38. Renz, J.; Rohloff, T. OpenSAP—der Enterprise-MOOC-Pionier. In Machen MOOCs Karriere? Eine Praxisnahe Reflexion über Erfahrungen von Unternehmen; Deimann, M., Friedl, C., Eds.; Springer Gabler: Wiesbaden, Germany, 2020.

39. Ong, D.; Jambulingam, M. Reducing employee learning and development costs: The use of massive open online courses (MOOC). Dev. Learn. Organ. Int. J. 2016, 30, 18-21. [CrossRef]

40. Hamori, M. MOOCs at work: What induces employer support for them? Int. J. Hum. Resour. Manag. 2019, 1. [CrossRef]

41. Park, S.; Jeong, S.; Ju, B. MOOCs in the workplace: An intervention for strategic human resource development. Hum. Resour. Dev. Int. 2018, 12, 1-12. [CrossRef]

42. Denzin, N.K.; Lincoln, Y.S. The Sage Handbook of Qualitative Research; Sage Publications: Thousand Oaks, CA, USA, 2005.

43. Flick, U. An Introduction to Qualitative Research; Sage Publications: Thousand Oaks, CA, USA, 2009.

44. Babbie, E.R. The Basics of Social Research; Wadsworth Cengage Learning: Belmont, CA, USA, 2013.

45. MAXQDA. 2018. Available online: https://www.maxqda.com/blogpost/just-released-maxqda-2018 (accessed on 14 June 2021 ).

46. Venkatesh, V.; Morris, M.G.; Davis, G.B.; Davis, F.D. User acceptance of information technology: Toward a unified view. MIS Q. 2003, 27, 425-478. [CrossRef]

47. Hasenauer, C. Die Expedition Lernen. Eine virtuelle Lernreise der Erste Bank der österreichischen Sparkassen AG. In Machen MOOCs Karriere? Eine Praxisnahe Reflexion über Erfahrungen von Unternehmen; Deimann, M., Friedl, C., Eds.; Springer Gabler: Wiesbaden, Germany, 2020.

48. Hörn, P.; Günther, F.; Dückert, S. MOOC Zusammenarbeit 2.0 bei Audi-ein Erfahrungsbericht. In Machen MOOCs Karriere? Eine Praxisnahe Reflexion über Erfahrungen von Unternehmen; Deimann, M., Friedl, C., Eds.; Springer Gabler: Wiesbaden, Germany, 2020.

49. Padilla Rodriguez, B.; Fernández-Cárdenas, J.M. Developing Professional Competence at a Mexican Organization: Legitimate Peripheral Participation and the Role of Technology. Procedia Soc. Behav. Sci. 2013, 69, 8-13. [CrossRef]

50. Battistelli, A.; Odoardi, C.; Vandenberghe, C.; Di Napoli, G.; Piccione, L. Information sharing and innovative work behavior: The role of work-based learning, challenging tasks, and organizational commitment. Hum. Resour. Dev. Q. 2019, 30, 361-381. [CrossRef]

51. Deimann, M.; Friedl, C. Machen MOOCs Karriere? Eine Praxisnahe Reflexion über Erfahrungen von Unternehmen; Springer Gabler: Wiesbaden, Germany, 2020. 
52. Renz, J.; Schwerer, F.; Meinel, C. OpenSAP: Evaluating xMOOC usage and challenges for scalable and open enterprise education. In Proceedings of the Eighth International Conference On E-Learning in the Workplace 2016, New York, NY, USA, 15-17 June 2016.

53. Strother, J.B. An assessment of the effectiveness of e-learning in corporate training programs. Int. Rev. Res. Open Distrib. Learn. 2002, 3. [CrossRef]

54. Mendoza, G.A.G.; Jung, I.; Kobayashi, S. A review of empirical studies on MOOC adoption: Applying the unified theory of acceptance and use of technology. Int. J. Educ. Media Technol. 2017, 11, 15-24.

55. Wang, Q.Y.; Mao, H.B. An Analysis of the Factors that Affect MOOC Learning Behavior Based on UTAUT Model. e-Educ. Res. 2016, 9 .

56. Jansen, D.; Rosewell, J.; Kear, K. Quality Frameworks for MOOCs. In Lecture Notes in Educational Technology; Springer: Berlin/Heidelberg, Germany, 2017; pp. 261-281.

57. Renz, J.; Rohloff, T.; Meinel, C. Automatisierte Qualitätssicherung in MOOCs durch Learning Analytics. In Proceedings of the DeLFI and GMW Workshops 2017, Chemnitz, Germany, 5 September 2017; Ullrich, C., Wessner, M., Eds.; Gesellschaft für Medien in der Wissenschaft: Chemnitz, Germany, 2017.

58. Bogdan, R.; Holotescu, C.; Andone, D.; Grosseck, G. How MOOCs are being used for corporate training? In Proceedings of the the 13th International Scientific Conference eLearning and Software for Education. pp. 405-410. Available online: https: / / proceedings.elseconference.eu/ (accessed on 14 June 2021).

59. Gori, S. Discover Social Learning: Kurs und Community für Ausbildungsverantwortliche. In Machen MOOCs Karriere? Eine praxisnahe Reflexion über Erfahrungen von Unternehmen; Deimann, M., Friedl, C., Eds.; Springer Gabler: Wiesbaden, Germany, 2020.

60. Friedl, C.; Staubitz, T.; Jansen, D. Flexible, self-directed and bottom-up: Are employees overtaking their human resource departments with MOOCs? In Learning with MOOCs Conference Proceedings; IEEE: Madrid, Spain, 2018.

61. Hamori, M. Can MOOCs Solve Your Training Problem? Harv. Bus. Rev. 2018, 6, 1687392.

62. Shah, D. MOOC Trends in 2017: Online Degrees and Corporate Learning. In Class Central. 2018. Available online: https: //www.class-central.com/report/mooc-trends-online-degrees-corporate-learning/ (accessed on 2 August 2020). 